\title{
Remotando el 32 \\ De la represión a la supresión
}

\author{
Rafael Lara-Martínez \\ Tecnológico de Nuevo México \\ Desde Comala siempre... \\ soter@nmt.edu
}

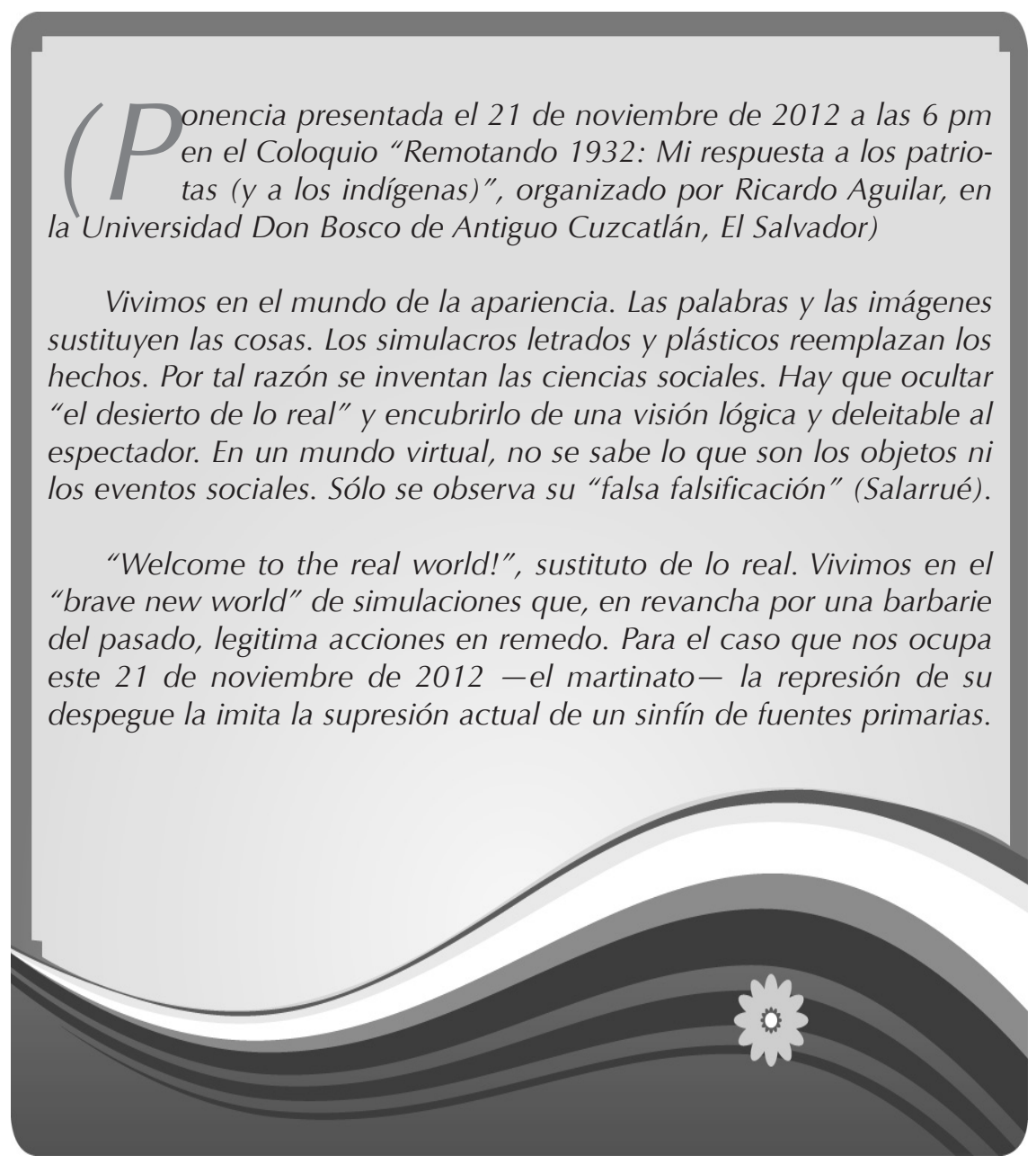


La historia cultural de El Salvador oscila de la represión militar del pasado a la supresión intelectual del presente. Así se autoriza que una cultura nacional indigenista - en apoyo a un régimen fascista - la reciclen la izquierda y el marxismo.

"El doble del dictador" - su espectro vivo - "rige" como Patriarca muerto sobre la herencia cultural salvadoreña hasta el siglo XXI. Su espíritu vivaz cautiva el corazón de sus críticos de izquierda y de sus enemigos marxistas. A continuación se desglosa la manera en que sucede esta coincidencia de los opuestos en materia de identidad nacional. Los marxistas copian a los fascistas en un simulacro de "espejos paralelos".

\section{I.}

En diciembre de 1931, el ascenso de Maximiliano Hernández Martínez lo apoyan casi todos los intelectuales antiimperialistas de Centroamérica. El primer escritor que habla de la Matanza en público - el costarricense Juan del Camino en el Repertorio Americano- califica el golpe de estado de "ejemplo viril" contra el imperialismo estadounidense.

En enero de 1933, un juicio político semejante lo declara el socialista Vicente Sáenz en México. Según este otro costarricense, todos los intelectuales salvadoreños respaldan la política antiimperialista de su presidente, el general Martínez, quien representa el eslabón más fuerte para "romper las cadenas, las del imperialismo yanqui en Centroamérica". La retórica antiimperialista opaca la conmemoración de la Matanza en enero de 1933.

El silencio lo certifica Gabriela Mistral en su único artículo sobre El
Salvador, publicado originalmente en Chile y en Costa Rica. Desde Italia, la futura premio Nobel recuerda el sabroso café salvadoreño que prueba en septiembre de 1931, durante una apoteosis del indigenismo nacional financiada tardíamente por el general Martínez (Diario Oficial, 23 de junio de 1933).

Pero no sólo el imperialismo yanqui acecha el istmo, ya que "el oso ruso" —según el decir sandinista de Gustavo Alemán Bolañostambién promueve un "levantamiento de venganza" (Salarrué). Por tal asedio, en México, el indigenismo de Miguel Ángel Espino defiende la legítima defensa contra el imperialismo soviético que asalta la nación salvadoreña, mientras Alejandro Dagoberto Marroquín trabaja en la Gobernación del Departamento de La Libertad por Decreto Ejecutivo (Diario Oficial, 9 de febrero, 12 de septiembre y 9 de noviembre de 1932 para Espino y 25 de febrero de 1932 para Marroquín). 
Ante la doble amenaza, la respuesta de El Salvador presupone una cometida dual en metáfora de la autoridad familiar. Es necesario el castigo del Padre, el del estado, y el consuelo de la Madre, el de la nación. Según la alegoría salarrueriana, el Padre, el estado, reprime; la Madre, la nación, conforta ("Los que no entendemos. El sentido común", sin fecha ni editorial, cortesía de Ricardo Aguilar).En 1932, para las redes intelectuales teosóficas y la iglesia católica, la sanción paterna justifica la Matanza en legítima defensa por la soberanía nacional.

"Matan a sangre fría [...] los peores asesinos. Por eso merecen condena eterna todos los hechos sangrientos hace algunos meses ejecutados por forajidos [...] es una dolorosa equivocación creer que el comunismo se practica segando vidas y arrasando propiedades. Esas doctrinas que tuvieron origen en el Sermón de la montaña, no son de destrucción sino de conservación [...] Esto lo han ignorado [...] nuestros campesinos por eso han delinquido [...] y se dejaron llevar al sacrificio de su vida" (Eugenio Cuéllar cuyo cuento lo ilustra Pedro García V., quien diseña varios "cuentos de barro". Cypactly, No. 17, 22 de junio de 1932).

Quienes deciden "lanzarse a desantentadas rebeldías obedeciendo azuzamientos subversivos [de los comunistas] sólo les dejan saldos de miseria y muerte" (Cypactly, No. 19, 31 de julio de 1932).
El acto represivo del padre lo subsana la Mater Dolorosa. El alivio materno se intitula "La hora de los maestros" (Salvador Cañas, Cypactly, 1932). Suprimida la amenaza comunista —la "ola roja" de violencia en la "selva roja" - hay que forjar patria (Machón Vilanova y Salarrué). "Fue preciso que la tragedia surgiera, para que supiéramos [...] los hombres de letras [...] sugerir ideales" de identidad nacional (Cañas). Tal labor de la "política de la cultura" es "la obligación del "intelectual en el amplio sentido de la palabra" (Quino Caso).

Ese intelectual se Ilama Salarrué. Sus "cuentos de barro" los reproducen las publicaciones oficiales en muestra de una "política de la cultura". Esta nueva "política del espíritu" se organiza alrededor de las revistas oficiales como el Boletín de la Biblioteca Nacional.

En dicha revista no sólo se anticipa la publicación del libro con los relatos "El negro", "El damo", "La botija" y "El Cheje", en demostración de un reconocimiento estatal a su narrativa. También se difunden juicios laudatorios oficiales sobre su obra, los cuales luego se repiten nombre de lo popular-socialista.

No se trata de una nueva alianza del "soldado y el letrado". Desde la década de los veinte el general - "lector de la filosofía indostana" - y el escritor — "entusiasta de la Teosofía" - comparten espacios 
intelectuales comunes (J. Gómez Campos, Semblanzas salvadoreñas (1930) y Revista Excelsior).

La reseña de mayor relevancia política se intitula "Escritores salvadoreños: Salarrué", la cual la escribe Quino Caso, el teniente Joaquín Castro Canizález, miembro del "Directorio Militar" en diciembre de 1931, quien "controla los asuntos nacionales", incluso la literatura (mayo de 1932). Su obra pictórica la ensalza Luis Alfredo Cáceres Madrid, "Salarrué colorista", quien se dedica a "culturizar la tropa" junto a su colega indigenista José Mejía Vides.

La "política del espíritu" requiere que los intelectuales se comprometan en desarrollar la nación por un "leer y escribir" masferreriano. Hay que construir un canon literario y pictórico que exalte los valores nacionales. A los escritores y artistas les corresponde rescatar las tradiciones campesinas e indígenas para plasmarlas en el lienzo, en la poética y en la música. Tal es la solicitud que Cypactly. Tribuna del Pensamiento Libre de América les extiende a sus colaboradores, a los intelectuales teósofos.

Si sus contribuyentes son los "ungidos", la petición de Cypactly significa la formación de una cultura nacional arraigada en lo popular. "Francisco Gavidia, Salarrué... cuántos y cuántos, todos los ungidos, las almas luminosas de nuestra patria, ungen y consagran con sus plumas estilistas las páginas de Cypactly (Lydia Valiente, Cypactly, No. 13, 20 de marzo de 1932). Las figuras fundadoras de la literatura nacional salvadoreña colaboran en esa "tribuna del pensamiento libre de América" que legitima la Matanza en nombre del antiimperialismo. La soberanía nacional autoriza la legítima defensa.

Los requisitos que Cypactly le impone al arte nacional equivalen a la exigencia política que solicitan los comprometidos décadas después. Se trata de la re-presentación y recolección (Logos) de una cultura popular y democrática. Hay que prestarle "atención a las cosas nuestras para trasladarlas al libro, al lienzo, al pentagrama" reconociendo "la riqueza" que genera "la clase proletaria" - (Cypactly, No. 11, 10 de febrero y No. 18, 10 de julio de 1932, nótese el uso de la terminología marxista que la reitera oficialmente La República. Suplemento del Diario Oficial).

En eco cercano a la multicitada "Mi respuesta a los patriotas", los intelectuales teósofos apoyan un gobierno neutral. Su obra no favorece a los "crueles comunistas pedigüeños" que "hablan de degollar" para imponer "la justicia", ni a los "capitalistas embrutecidos" que sólo piensan en "el mercado". Hacia 1932, se insinúa que el régimen del general Martínez establece un balance socialista radical entre 
"la tesis proletaria" del "trabajo como fuente de riqueza" y "la tesis burguesa" del "capital" en una "democracia integral" (lugares citados).

II.

Si la multicitada "Mi respuesta a los patriotas" vindica "al indio del arado y la cuma", es porque "nada tiene" ni reclama. "Está satisfecho de hacer vivir" con su trabajo sin alzarse en armas como los "embrutecidos degolladores" que exaltan a la revuelta.

Si la multicitada "Mi respuesta a los patriotas" vindica a "la mujer soñadora", es porque carece de voto, del derecho político más elemental de una democracia electoral. Junto al "indio contemplativo", la fémina no hace política. "La política no sólo es infructuosa sino dañina" a quien la ejercita.

Quizás por defender la pasividad vegetal, apolítica superior, de los indígenas y las mujeres, la multicitada "Mi respuesta a los patriotas" la ignoran todas las "Actividades literarias en el año de 1932" que reseña Juan Felipe Toruño en el Boletín de la Biblioteca Nacional (1934) y en la Revista del Ateneo de El Salvador (1932).

Como redactor de la revista de la Logia Téotl —a la cual pertenecen Salarrué, el general Martínez, etc.-Toruño desempeña el papel del intelectual orgánico, estrechamente ligado al ascenso y a la presidencia del general Martínez.
Así lo testimonia el único escritor marxista estalinista — Miguel A. Ibarra en Cafetos en flor (1947) — cuya obra la tacha adrede la izquierda salvadoreña.

La multicitada "Mi respuesta a los patriotas" no sólo sirve para rechazar la historia, esto es, justifica borrarla recepción temprana que goza la obra de Salarrué en los círculos oficiales del martinato. También sirve para ocultar las otras actividades de Salarrué en 1932. Nadie refiere las múltiples reseñas que recibe su indigenismo y fantasía —en literatura y en pintura- de sus contemporáneos y primeros espectadores.

Basta citar que el primer antólogo de Salarrué, Hugo Lindo (1969-1970), excluye la estrecha relación entre su narrativa y el 32 que hoy se le atribuye; o que un crítico estadounidense de prestigio, Seymour Menton (1964), entrevé en "La botija" una burla socarrona de un campesino hecho payaso. Toda lectura temprana de Salarrué contradice la interpretación actual. No existe una obra sin lectores ni intérpretes contemporáneos, quienes jamás la perciben como una crítica social de la Matanza.

No sólo ese aspecto histórico ignora la multicitada "Mi respuesta 
a los patriotas". La aburrida cita que se re-cita también sirve para descalificar todas las demás "actividades literarias [que] en el año de 1932" realiza Salarrué. Sirve de excusa para hacer historia sin historiografía. Ya se anotaron la serie de cuentos y dos reseñas oficiales de 1932, las cuales demuestran que los juicios laudatorios sobre Salarué los inician las revistas ligadas al régimen del general Martínez, antes que los repita la generación comprometida en la continuidad de su ruptura.

Falta agregar la publicación de Remotando el Uluán, la única novela de Salarrué en 1932, su participación en los actos oficiales del Centenario de José Matías Delgado y de Goethe, junto a las autoridades gubernamentales y de la Universidad de El Salvador, al igual que la exhibición de "muñecas indígenas" que dan risa, junto a Zelie Lardé (Cypactly, 20 de marzo de 1932 y 22 de junio de 1932). Son "tan graciosos que hacen reír al más triste".

Si en Cypactly lo indígena hecho monigote es lo cómico y lo irrisorio - tal cual lo refrenda Menton años después- el Centenario revalida el juicio de Quino Caso quien hace de Salarrué el escritor cuya "labor intelectual" resulta precisa para refundar la nación luego de "imprevistos y fatales sucesos". Sólo un "alma solitaria y complicada" quien "como Platón" y "Goethe tiene su Atlántida" - podría encarnar una tarea tan "inquietante" como expresar el "espíritu sabio" de El Salvador. En "esta hora americana de profundas y trascendentales renovaciones" —según cita de León Trotsky - un "hombre y su pensamiento" nos salva.

La única novela de Salarrué en 1932 siempre se juzga como pura fantasía. Pero la fantasía masculina por excelencia siempre se arraiga en el cuerpo sexuado de la mujer. El viaje astral del escritor místico lo propulsa una experiencia sexual con una "bella" afro-descendiente desnuda. La vivencia más espiritual del teósofo la estimula el apetito por lapródiga carne femenina.

"Abriendo aguas vírgenes [...] tras algunas caricias y mimos [en el] fulbultaje musical con Gnarda, perfectamente negra y perfectamente bella", Salarrué remonta "el Uluán"; "encantador el viaje" de ingreso "a las nebrunas sensuales y a las alectaras sensitivas" de "la minería" femenina. "Se unieron nuestros labios y nos besamos [...] desde aquel día fue para mí doblemente encantador el viaje [...] habiendo llegado una mañana a [...] una abertura circular que tenía el aspecto de laguna".

La fantasía revela un aspecto étnico y de género acallado por el miedo del marxismo salvadoreño a reconocer el cuerpo humano y el deseo. El hombre blanco se deleita de su poder sexual sobre una "mujer negra". Bastaría cambiar el género 
de la cita precedente —Zelie Lardé fornicando con un "hombre negro" en el encanto de su "abertura circular" - para que la experiencia místico-sexual se vuelva escándalo.

1932 se resuelve en la disparidad étnica y de género: hombre blanco vestido vs. mujer desnuda negra o de color como relación de clase. O si se prefiere, la lascivia del Conquistador se satisface en la desnudez de La Chingada, la primera comunista de América (Alemán Bolaños y Machón Vilanova).

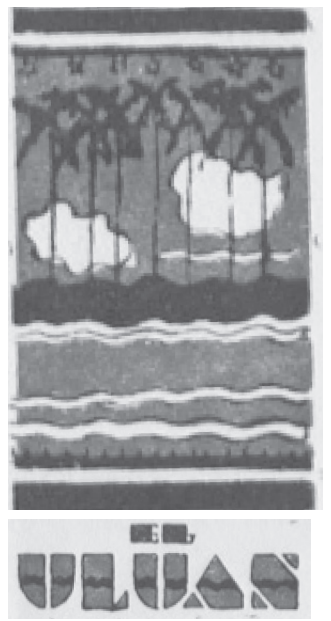

Viñeta de Remotando el Uluán (1932) la única novela corta de Salarrué, publicada en un año clave, pero excluida de todo comentario sobre los sucesos de 1932. El viaje astral reseña su relación étnicosexual con Gnarda, una "bella mujer negra desnuda", y el encuentro con múltiples grupos étnicos en su mayoría femeninos, de colores exóticos, y de carácter sensual. Parecería que ocultar el trasfondo étnico y sexual de los asuntos sociales sería una manera de escribir la historia.

\section{IV.}

Yo no sé si el marxismo salvadoreño es materialista, un materialismo sin cuerpo biológico ni sexuado. Pero tengo la certeza que es a-histórico. Se arraiga en una tradición cultural cercana al fascismo, en vez de indagar un legado revolucionario que data de 1932.

Por tal razón, no busca a sus antecesores entre los miembros del Socorro Rojo Internacional, ni entre los sindicalistas. De ahí que un testimonio como el escrito del marxista estalinista Miguel A. Ibarra permanezca adrede bajo el silencio.

Desde la generación comprometida hasta el 2012, los juicios laudatorios sobre Salarrué repiten las reseñas que publican las revistas oficiales del martinato y los periódicos teosóficos autónomos que apoyan la Matanza como acto de autonomía nacional.

Empero, para que la visión en boga sea verosímil, hay que borrar. Hay que ejercer una nueva inquisición y quemar los archivos naciona- 
les. El general Martínez reprime; la actualidad suprime. He ahí el cambio radical que vivimos en el 2012.

Se trata de encubrir la presencia idolatrada "del dictador" en "la política de la cultura" de la izquierda salvadoreña. El general Martínez sentaría la pauta añorada por el marxismo en su ideal de crear una cultura nacional letrada que represente lo indígena y lo popular. El general Martínez vive en el imaginario cultural de la izquierda salvadoreña como el Mal necesario (Matanza, dictadura...) que produce un Bien ineludible (cultura artística nacional celebrada en todos los museos capitalinos).

En su círculo de la añoranza, el marxismo salvadoreño no sólo sella su carácter re-volucionario y sinódico originario, en el eterno retorno de lo mismo. También confirma la propuesta salarrueriana más recóndita, a saber: la de un sujeto pos-cartesiano escindido.

Para Euralas, un espejo paralelo al Yo le entrega su verdadera identidad desgajada en una imposible conjunción de los opuestos. El marxismo del siglo XXI abraza el fascismo en su búsqueda de un Patriarca muerto, de un nuevo líder vivo que logre la unidad nacional alrededor de todos los intelectuales...

Agradecimientos: Le agradezco a la Fundación AccesArte hacer posible mi presencia corporal esta noche, en remplazo de mi habitual estancia astro-virtual en El Salvador. 